\title{
25 Research Square \\ Polymorphism of MUC1 gene in Vietnamese gastric cancer patients: a case-control study
}

\author{
Lan Thi Ngoc Nguyen \\ Hanoi Medical University \\ Dzung Thi Ngoc Dang ( $\nabla$ ngoczung@hmu.edu.vn ) \\ Hanoi Medical University \\ Van Thanh Ta \\ Hanoi Medical University \\ Huy Quang Dang \\ Hanoi Medical University \\ Chuc Van Tran \\ Hanoi Medical University \\ Masamitsu Yamaguchi \\ Kyoto Institute of Technology
}

Research article

Keywords: gastric cancer, polymorphism, rs4072037, rs2070803, MUC1 gene, Mucin 1 gene

Posted Date: September 10th, 2019

DOl: https://doi.org/10.21203/rs.2.14183/v1

License: (c) (i) This work is licensed under a Creative Commons Attribution 4.0 International License.

Read Full License 


\section{Abstract}

Background Gastric cancer is a malignant type of cancer associated with many factors such as environment, behavior, infection, and genetics, which include Single Nucleotide Polymorphism. A few studies revealed polymorphisms of the Mucin 1 gene have a role and significance as a susceptible factor contributing to gastric cancer. The aim of this research is to evaluate the association between Single Nucleotide Polymorphisms of the Mucin 1 gene and Vietnamese gastric cancer patients.Methods 302 gastric cancer patients and 304 controls were interviewed for social-economic characteristics, smoking and drinking status, personal and family history of gastric diseases. Genotyping was done using polymerase chain reaction-restriction fragment length polymorphism analysis. The association of Single Nucleotide Polymorphisms with gastric cancer was evaluated using multifactor regression models. Results AA genotype for rs4072037 was found to be highly associated with gastric cancer (OR: 2.07 (95\% Cl: 1.46-2.90). GG genotype for rs2070803 increased the risk of gastric cancer (OR:1.96 (95\% Cl: 1.37-2.78). These genotypes in combination with other factors such as old age, male gender, alcoholism and personal history of gastric disease also showed an increased risk of having gastric cancer.Conclusions rs 4072037 and rs2070803 of Mucin 1 genes are two genotypic risk factors of gastric cancer. Those in combination with other factors such as gender, family history, smoking and drinking habits significantly increase the risk of gastric cancer.

\section{Background}

Gastric cancer is a heterogeneous, multi-factorial, highly malignant type of cancer. In Vietnam, the high incidence rate and poor prognosis of the disease account for about 18,000 new cases and 15,000 deaths in 2018 according to Globocan (1). The multistep process of gastric carcinogenesis starts from chronic inflammation, followed by multifocal atrophic gastritis with intestinal metaplasia, dysplasia, and ends with gastric adenocarcinoma (2). Well-established pathological and environmental risk factors of gastric cancer include Helicobacter pylori (H. pylori) (2,3), smoking (4), and poor diet (5). In recent years, special focus has been shifted to identification of genetic factors, characterized by single-nucleotide polymorphisms (SNPs), which exist in large numbers in the human genome (6-8). Several genome-wide association studies have indicated the association between gastric cancer and SNP of the Mucin 1 (MUC1) gene, which codes for cell surface glycoprotein mucin-1 and is used in clinical settings as tumor marker C15-3, in some Asian and European populations $(6,9,10)$. Two SNPs rs4072037 and rs2070803 of the MUC1 gene were found to be associated with increased gastric cancer susceptibility. Despite a high incidence rate of gastric cancer, to date, genetic association study with a particular interest in the association between gene SNPs and gastric cancer in Vietnamese population is still very limited (11). It is, therefore, necessary to take advantage of the advancement in molecular targeted treatment technologies to gain an understanding of the genetic factors associated with the disease in order to develop new and more efficient therapeutic targets. For that purpose, we aimed to investigate the potential association of 2 SNPs of the MUC1 gene with gastric cancer risk and evaluate the combination factors relation with these SNPs. 


\section{Methods}

The case-control study involving 302 cases and 304 controls was conducted from 2016 to 2018 in four national hospitals in Hanoi, Vietnam. Diagnosis of cases was based on histopathology confirmation. The control group included people who were endoscopically diagnosed with normal epithelial gastric or only acute gastritis. The participants were explained about the purpose, the benefits, the drawbacks and the confidentiality aspect of participating in the study and had given their consent. Prior to the interview, there was a training process for conducting the research questionnaire, which aimed at investigating patients' socioeconomic and disease characteristics, and medical records procedure for researchers; the training consisted of a minimum of 24 hour training time, mock interviews and lead researcher's approval.

We asked the participants for their socioeconomic information including gender, age, educational status, occupation, personal and family's medical history, alcohol usage and smoking habit. Family history of participants included: Family history of gastric cancer, the number of family members having gastric cancer, their time of diagnosis and their relationship with the participants. Smoking history and alcohol abuse history were investigated using standards from the Center for Disease Control and Prevention and the World Health Organization, respectively $(12,13)$.

\section{DNA extraction}

Peripheral venous blood samples in EDTA containers were acquired from all subjects and were stored in appropriate condition before being transported to the Quality control center for Medical laboratories Hanoi Medical University for gene analysis. We extracted the genomic DNA from peripheral blood lymphocytes using Exgene ${ }^{\mathrm{Tm}}$ Blood SV Kit (Gene All, Korea). Following the manufacturer's protocol, we isolated the genomic DNA and stored them at $-80^{\circ} \mathrm{C}$ until SNPs analysis of the MUC1 gene.

$50 \%$ of the samples were sent to the Kyoto Institute of Technology for gene analysis using the same method, and $10 \%$ of the samples were analyzed in both laboratories for cross-checking.

\section{Detection of $M U C 1$ gene polymorphism}

The two MUC1 genotype polymorphisms (rs4072037 and rs2070803) were determined by polymerase chain reaction-restriction fragment length polymorphism (PCR-RFLP) method with PCR primer pairs listed in Table 1

The PCR was carried out in a 30 $\mathrm{L}$ reaction mix containing $100 \mathrm{ng}$ DNA template, 1 unit of Taq

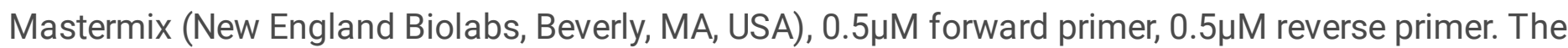
$\mathrm{PCR}$ reaction was carried out in a thermocycler and reaction conditions consisted of $95^{\circ} \mathrm{C}$ denaturation for 5 minutes, $94^{\circ} \mathrm{C}$ annealing for 30 seconds, $62^{\circ} \mathrm{C}$ annealing for 30 seconds, $72^{\circ} \mathrm{C}$ annealing for 30 seconds ( 40 cycles) and $72^{\circ} \mathrm{C}$ elongation for 10 minutes. The PCR products were digested with appropriate restriction enzymes (New England BioLabs, Beverly, MA, USA) at $37^{\circ} \mathrm{C}$ for 8 hours. The restriction enzymes were A/wM (rs4072037 G/A), Taqal (rs2070803 G/A). The PCR and digestion 
products were analyzed with a $1.5 \%$ agarose (Serva - Germany) gel with intercalating dye (ethidium bromide) staining. Selected PCR-amplified DNA samples (about 5\%) were analyzed by DNA sequencing (Fig. 1)

\section{Statistical analysis}

Data were analyzed using STATA 12.0 (Stata Corp. LP, College Station, TX, USA). Socio-economic information, medical history, characteristic of gastric cancer disease of participants were described. Distribution of the 2 SNPs following Hardy - Weinberg equilibrium. We used student's t-test and chisquare for evaluation of the differences in the distributions of demographic characteristics, selected variables, and genotypes of the rs4072037 and rs2070803 between the cases and the controls. After that, we estimated the associations between the 3 genotypes of SNPs and risk of gastric cancer by computing the odds ratios (ORs) and their 95\% confidence intervals (Cls) using unconditional logistic regression model.

\section{Results}

\section{Socioeconomic characteristics of participants}

A total of 606 participants were investigated in both groups, with male significantly outnumber female by 2 to 1 . There was a significant difference between the control and case subjects in terms of personal history of gastric cancer, family history of gastric cancer, and history of alcoholism. In contrast, a high level of similarity was observed in terms of age and gender distribution, with the $p$ values of 0.81 and 0.16 , respectively (Table 2 ).

The logistic regression model of multiple environmental factors demonstrates a significant association between gastric cancer and family history of gastric cancer with $\mathrm{OR}=3.69(95 \% \mathrm{Cl}: 1.78-7.66)$. Alcohol abuse and history of $\mathrm{H}$. Pylori infection also displayed significant association with the odds ratio being 0.5 and 0.42 respectively. Other factors including gender, age group, smoking history, and gastritis history showed insignificant results despite significant associations in some cases such as history of gastritis and gender.

\section{Distribution of participants' genes and alleles}

For rs4072037, the most common genotype among the case group was AA (49.34\%), whereas, in the control group, the majority of patients was found to have AG genotype (53.29\%). There was also a significant difference in the frequency of alleles between the two groups $(p=0.02)$. Similarly to rs4072037, rs2070803 results indicated differences in genotypes between the two groups, with predominantly identification of AG in the control group (53.95\%) and GG in the case group (45.69\%). The differences in those genotypic distributions were both statistically significant $(p=0.00)$ (Table 4) 


\section{Gastric cancer risk related genotypes and alleles}

In rs4072037, participants with AA genotype had higher gastric cancer risk compared to patients with AG and a combination of $A G+G G$ with $O R=2.09$ (95\% Cl: 1.48-2.96) and $O R=1.85$ (95\% Cl: 1.33-2.56), respectively. In rs2070803, GG genotype increased gastric cancer risk when compared with AG and AG+AA, OR=1.97 (95\% Cl: 1.39-2.80) and 1.71 (95\% Cl: 1.23-2.39), respectively. AG genotypes in both SNP decreased gastric cancer risk when compared with homogenous genotype, more specifically AA with $\mathrm{OR}=0.51(95 \% \mathrm{Cl}: 0.35-0.72)$ and GG with OR=0.58 (95\% Cl: 0.35-0.97), respectively (Table 5)

AA genotype of rs4072037 in combination with factors include age $>60$, male gender, alcohol abuse history, personal history gastritis, and family history of gastric cancer significantly increased gastric cancer risk with adjusted OR from 1.57 to 6.47 . AA genotype in combination with a family history of gastric cancer was the highest risk factor with $\mathrm{OR}=6.47$ (95\% Cl: 2.21-18.89). GG genotype of rs2070803 combine with family gastric cancer history increased gastric cancer risk with OR=6.18 (95\% Cl: 2.11 18.10) (Table 6)

\section{Discussion}

Two SNPs rs4072037 and rs2070803 of the MUC1 gene were found to be genotypic risk factors of gastric cancer. Those SNPs in combination with other socioeconomic risk factors show a significantly increased risk of gastric cancer.

Genotypic distribution of the patient group from our study was found to be similar to the one reported by Song et al. in 2014, and Zhang et al. in 2011, with AA being the most common genotype $(14,15)$. The results indicated the association between allele A of rs4072037 and an increased risk of gastric cancer. The risk was also elevated in the AA genotype group. Our results were supported by research done by Xu et al. in 2009 (16), by Jia et al. in 2010 (17), by Palmer et al. in 2013, and by Song et al. in $2014(18,19)$. Higher risk of cancer in patients with allele A compared to those with allele $\mathrm{G}$ was also pointed out by Saeki et al. in 2011 (27). On the contrary, a decreased risk of gastric cancer in patients with the $G$ allele was found in research by Abnet et al. in 2010, and Shi et al. in 2011 (20, 21). This result was similar to multiple studies in Japanese, Korean, and Chinese population (OR ranging from 0.26 to 0.69$)(15,22,23)$. The rs 4072037 located in the 5 ' end of the 2 nd exon of $M U C 1$ gene allows determination of the splicing point. The $\mathrm{G}$ allele and the A allele belong to two different variants: 2 and 3, respectively. Via mutation of amino acids in the $2^{\text {nd }}$ exon, the structural differences between the two variants affect the N-terminal signal peptide, which in turn lead to a variation in function of the encoded protein. The A allele associates with gastric cancer by lowering MUC1 expression on the surface of epithelial cells lining the gastric mucosa. Mucins play a crucial role in forming protective mucous barriers on the epithelial surface of the stomach. The low expression of $M U C 1$ may increase susceptibility to gastric cancer due to the reduced protective function of the stomach $(24,25)$. 
As for rs2070803, in comparison with research by Fang Li et al. in 2012, despite a difference in genetic distribution, there was a similarity regarding the higher risk of gastric cancer in GG genotype when compared to $A A+A G$ genotype $O R=0.46(95 \% \mathrm{Cl}=0.32-0.67)(26)$. The quantification of association between alleles and gastric cancer risk show $\mathrm{G}$ compared to $\mathrm{A}$ with $\mathrm{OR}=2.73$ but with no significant $\mathrm{p}$ value. On the contrary, the research by Saeki et. al in 2011 with 3 independent data sets: Tokyo, Aichi, and Korea demonstrate a significant association between allele $\mathrm{G}$ and both intestinal and diffuse gastric cancer (27). This difference may be due to the limited sample size of the study. Rs 2070803 on the $1 \mathrm{q} 22$ chromosome is an SNP located in between MUC1 and Tripartite Motif Containing 46 (TRIM46), both of which locate in a region of strong disequilibrium and are convergently transcribed (28). Numerous sources have reported the association between MUC- 1 and the carcinogenesis of various tumor including gastric cancer $(29,30)$. However, there is no expression of TRIM46 in the gastric mucosa. This suggests rs2070803 being a tagging SNP for variants in $M U C 1$ gene, which are associated with gastric carcinogenesis.

Regarding combinations of risk factors, old age (>60 years old) together with AA genotype of rs 4072037 and GG genotype of rs 2070803 showed a notable increase in gastric cancer risks with $\mathrm{OR}=1.57$ (95\% Cl: $1.05-2.34)$ and $\mathrm{OR}=1.5(95 \% \mathrm{Cl}: 1.00-2.25)$ respectively. The majority of gastric cancer is primary and occurs in patients between the ages of 60 and 80, especially in Eastern Asia region $(31,32)$. Research on the Vietnamese population also reports a high incidence rate of gastric cancer in elderly people (11). The cancer growth process may involve several risk factors with different time and levels with which cells are affected. The affected cells need to be able to survive the apoptosis program in the immune system so that they can divide and multiply until tumors are formed. Due to the better immune system and shorter exposure time to most environmental risk factors that can accumulate gradually, young people tend to have a significantly lower risk of cancer in comparison to the elderly.

Gastric cancer risk was found to be increased roughly 1.8 times $(p<0.05)$ when both genotypic (rs4072037 AA genotype or rs2070803 GG genotype) and gender (male) factors were considered. The gastric cancer incidence rate in males was reported to be approximately double that in females, particularly in countries with a high prevalence of gastric cancer. Various characteristics such as smoking, alcohol drinking, that attribute mostly to males, contribute to that fact (33). Another reason for the lower cancer rate in the female is the hormone estrogen, which was reported to have a protective effect in decreasing stomach cancer risk (34-37). A multicenter cohort study in Korea has pointed out similar results with isoflavone and phytoestrogen (38). This is further supported by several studies indicating an increased risk of gastric cancer in both genders treated with tamoxifen (an estrogen blocker) $(39,40)$. The result on the association between gastric cancer risk and a combination of MUC1 polymorphisms (rs4072037, rs2070803) and male gender once again showed that rs4072037 AA and rs2070803 GG are the two genotypic risk factor for stomach cancer. In our study, no notable association was found between history of alcohol abuse and gastric cancer; however, that factor together with rs4072037 AA genotype or rs 2070803 GG genotype both increased risk of gastric cancer significantly with $\mathrm{OR}=2.06(95 \% \mathrm{Cl}: 1.32-3.23)$ and $\mathrm{OR}=1.98(95 \% \mathrm{Cl}: 1.22-3.04)$. The effect of alcohol on gastric cancer is still in debate. Some empirical studies have suggested a carcinogenesis mechanism in which 
metabolic products of ethanol facilitate cancer risk factors penetration to damaged gastric mucosa, while other studies have pointed out possible protective function of ethanol due to its destructive effect on H.Pylori $(40,41)$. Research done on alcohol consumption rate and stomach cancer have shown divergent results, with a few authors pointing to heavy drinking of various alcohol-based beverage posing an even greater risk compared to standard alcohol (42-45).

Smoking is one of the primary risk factors that contribute to the manifestation of gastritis, atrophic gastritis, and gastric cancer in both the cardiac and non-cardiac region. Nishino et al. in 2006 have reported 1.56 times higher risk coming from patients with a history of smoking (46). According to Gonzalez, approximately $18 \%$ of gastric cancer cases can be traced back to heavy smoking. In addition, gastric cancer risk has been found to increase with long smoking time and decrease after 10 years of cessation (47). Tobacco smoke has been proven to be a mixture of many harmful chemicals relating to human gastric carcinoma (48). The smoking-related DNA adducts that bind to DNA of the gastric mucous membrane have been found in samples from smokers (49). The smoking risk factor together with AA genotype of rs4072037 and GG genotype of the rs2070803 increased risk of gastric cancer with $\mathrm{OR}=1.72$ (95\% Cl: $1.11-2.67)$ and $\mathrm{OR}=1.68(95 \% \mathrm{Cl}: 1.07-2.63)$ respectively. There are many studies supporting the high gastric cancer risk of patients that have a combination of genotypic risk factors (SNPs) and environmental factors (alcohol drinking/smoking). Research by Boccia et al. in 2007 has pointed out the increased gastric cancer risk in smokers with Sulfotransferase Family 1A Member 1 (SULT1A1) gene, and drinkers with CYRS2070803E1 gene (*5A allele or *6 allele) (50). Cyclooxygenase-2 (COX-2) polymorphisms together with a history of smoking play an important role in the development of gastric cardia adenocarcinoma (51). TNF-alpha-857 C/T genotypic polymorphism is an independent risk factor, and gastric cancer caused by tumor necrosis factor (TNF) gene has been argued to be related to smoking habit (52). Research by Xu et al. in 2014 has demonstrated a MUC1 mechanism, in which the inflammation signal is activated by macrophages, that contribute to the manifestation of lung cancer in patients who smoke (53).

Family history of gastric cancer is one of the major factors that double or even triple the risk of gastric cancer $(54,55)$. The percentage of patients who have a family history of gastric cancer in our research was $12.4 \%$, lower than other research done in Italian (21.9\%) (56), and Spanish population (17.6\%) (57). A study by Dhillon et al. in 2006 on 695 cases and 629 controls in America has estimated the association between gastric cancer and family history with $\mathrm{OR}=2.2(95 \% \mathrm{Cl}: 1.5-3.3)$. This is further increased in individuals who have 2 or more family member diagnosed with gastric cancer, with $\mathrm{OR}=12.1(95 \% \mathrm{Cl} 1.4-$ 108) (55). Nine studies that were done in Turkey, Italia, Finland, German, and Spain also show a significant connection with $\mathrm{OR}$ ranging from 1.8 to 10.1 depending on different countries (58-61). Five studies on Japanese population also demonstrate the same association with OR from 1.5 to $3.5(62,63)$. Our study also show similar result (Table 3), with OR $=3.69(95 \% \mathrm{Cl}: 1.78-7,66)$. The detailed mechanism of the cause and effect relationship between family history and gastric cancer is not fully understood; however, special focus has been put on genetic characteristics. In our research, patient with a family history of gastric cancer in conjunction with rs4072037 AA genotype and rs2070803 genotype elevate gastric cancer risk significantly with $\mathrm{OR}=6,47(95 \% \mathrm{Cl}: 2.21-18,89)$ and $\mathrm{OR}=6,18(95 \% \mathrm{Cl}: 2.11-$ 
$18,10)$, respectively. This indicates the importance of family history of gastric cancer as a major risk factor for gastric cancer, especially in combination with other genotypic risk factors of rs4072037 and rs2070803. Therefore, a classification of patients according to different kinds of risk factor is necessary for management, monitoring, and prevention of gastric cancer. This could be benefited by the implementation of a complete system that focuses on the management of cancer among individuals who have a history of cancer.

\section{Conclusions}

In summary, our case-control study investigated the effect of two SNPs rs4072037, rs2070803 in MUC1 gene as the risk factor for gastric cancer. It was found for the first time in the Vietnamese population that participants carrying rs4072037, rs2070803 polymorphisms would be more susceptible to gastric cancer. Furthermore, those genetic factors when interplay with some environmental factors such as smoking, alcohol abuse, and family history of gastric cancer significantly increase risk of having gastric cancer.

\section{Abbreviations}

\section{MUC1 Mucin 1}

SNP Single Nucleotide Polymorphism

PCR-RFLP Polymerase chain reaction-restriction fragment length polymorphism

OR Odds ratio

Cl Confidence intervals

H. Pylori Helicobactor Pylori

TRIM46 Tripartite Motif Containing 46

SULT1A1 Sulfotransferase Family 1A Member 1

COX-2 Cyclooxygenase-2

TNF Tumor necrosis factor

\section{Declarations}

Ethics approval and consent to participate

This study was approved by the Ethics Council of Hanoi Medical University under decision number $198 / H Đ Đ Đ Đ H Y H N$ and the participants had given consent before the interview. 
Consent for publication

Not applicable

Availability of data and materials

The datasets generated during and/or analyzed during the current study are available from the corresponding author on reasonable request. Requests for access to these data should be made to Dzung Ngoc Thi Dang - Biochemistry Department, Hanoi Medical University, Hanoi, Vietnam - Email: ngoczung@hmu.edu.vn

Competing interests

The authors declare that they have no competing interests

Funding

This research is funded by the Vietnam National Foundation for Science and Technology Development (NAFOSTED) under grant number 106-YS.02-2015.37. The funding includes research design, samples, data collection, and gene analysis.

Authors' contributions

LN took part in designing the research, collected samples, analyzed and interpreted the participants' data regarding SNPs of gastric cancer and contributed to statistical analysis and writing the manuscript.

VT took part in designing the research and writing the manuscript.

HD was responsible for statistical analysis and writing the manuscript.

CT collected samples, analyzed and writing the manuscript

MY contributed to writing the manuscript and analyzed the samples

DD was responsible for research design and writing of the manuscript

All authors read and approved the final manuscript.

Acknowledgments

Not applicable

\section{References}

1. The L. GLOBOCAN 2018: counting the toll of cancer. Lancet. 2018;392(10152):985.

2. Zabaleta J. Multifactorial etiology of gastric cancer. Methods Mol Biol. 2012;863:411-35. 
3. Ishaq S, Nunn L. Helicobacter pylori and gastric cancer: a state of the art review. Gastroenterol Hepatol Bed Bench. 2015;8(Suppl 1):S6-S14.

4. Nomura AMY, Wilkens LR, Henderson BE, Epplein M, Kolonel LN. The association of cigarette smoking with gastric cancer: the multiethnic cohort study. Cancer Causes Control. 2012;23(1):51-8.

5. Ngoan LT, Mizoue T, Fujino Y, Tokui N, Yoshimura T. Dietary factors and stomach cancer mortality. Br J Cancer. 2002;87(1):37-42.

6. Saeki N, Sakamoto H, Yoshida T. Mucin 1 gene (MUC1) and gastric-cancer susceptibility. Int J Mol Sci. 2014;15(5):7958-73.

7. Nagini S. Carcinoma of the stomach: A review of epidemiology, pathogenesis, molecular genetics and chemoprevention. World J Gastrointest Oncol. 2012;4(7):156-69.

8. Deng N, Zhou H, Fan H, Yuan Y. Single nucleotide polymorphisms and cancer susceptibility. Oncotarget. 2017;8(66):110635-49.

9. Wang X-T, Kong F-B, Mai W, Li L, Pang L-M. MUC1 Immunohistochemical Expression as a Prognostic Factor in Gastric Cancer: Meta-Analysis. Dis Markers. 2016;2016:9421571-.

10. Boltin D, Niv Y. Mucins in Gastric Cancer - An Update. J Gastrointest Dig Syst. 2013;3(123):15519-.

11. Binh TT, Tuan VP, Dung HDQ, Tung PH, Tri TD, Thuan NPM, et al. Advanced non-cardia gastric cancer and Helicobacter pylori infection in Vietnam. Gut Pathog. 2017;9:46-.

12. Prevention CfDCa. Adult tobaco use information 2017 [

13. WHO. The Alcohol Use Disorders Identification Test (AUDIT) 2001 [

14. Song H.R., Kim H.N., Kweon S.S., et al. Common genetic variants at 1q22 and 10q23 and gastric cancer susceptibility in a Korean population. Tumour Biology. 2014;35(4):3133-7.

15. Zhang H., Jin G. Genetic variants at $1 \mathrm{q} 22$ and $10 \mathrm{q} 23$ reproducibly associated with gastric cancer susceptibility in a Chinese population. Carcinogenesis 2011. 2011:32: 848-52.

16. Xu QY, Y. et al. Risk of gastric cancer is associated with the MUC1 568 A/G polymorphism. Int J Oncol. 2009:35, 1313-20.

17. Jia YP, C. et al. A comprehensive analysis of common genetic variation in MUC1, MUC5AC, MUC6 genes and risk of stomach cancer. Cancer Causes Control. 2010:21, 313-21.

18. Palmer AJL, P. et al. Genetic variation in C20orf54, PLCE1 and MUC1 and the risk of upper gastrointestinal cancers in Caucasian populations. Eur J Cancer Prev. 2013:21, 541-4.

19. Song HRK, H.N. et al. Common genetic variants at $1 \mathrm{q} 22$ and $10 \mathrm{q} 23$ and gastric cancer susceptibility in a Korean population. Tumour Biol. 2014:35, 3133-7.

20. Abnet CC FNea. A shared susceptibility locus in PLCE1 at 10q23 for gastric adenocarcinoma and esophageal squamous cell carcinoma. Nat Genet 2010. 2010:42: 764-7.

21. Shi YH, Z et al. A genome-wide association study identifies new susceptibility loci for non-cardia gastric cancer at 3q13.31 and 5p13.1. Nat Genet. 2011:43, 1215-8.

22. Saeki $\mathrm{N}$ ea. A functional single nucleotide polymorphism in mucin 1 , at chromosome $1 \mathrm{q} 22$, determines susceptibility to diffuse-type gastric cancer. Gastroenterology, 140(3). 2011:892-902. 
23. Li M, Huang L, Qiu H, Fu Q, Li W, Yu Q, et al. Helicobacter pylori infection synergizes with three inflammation-related genetic variants in the GWASs to increase risk of gastric cancer in a Chinese population. PloS one. 2013;8(9):e74976.

24. Norihisa Saeki, Hiromi Sakamoto. Mucin 1 Gene (MUC1) and Gastric-Cancer Susceptibility. Int J Mol Sci, 15(5). 2014:7958-73.

25. Saeki N. A functional single nucleotide polymorphism in mucin 1, at chromosome 1q22, determines susceptibility to diffuse-type gastric cancer. Gastroenterology. 2011;140(3):892-902.

26. Fang Li, Mei-Zuo Zhong, Jian-Huang Li, et al. Case-control study of single nucleotide polymorphisms of PSCA and MUC1 genes with gastric cancer in a Chinese. Asian Pac J Cancer Prev 2012. 2012;13(6).

27. Saeki N, Saito A, Choi IJ, Matsuo K, Ohnami S, Totsuka H, et al. A functional single nucleotide polymorphism in mucin 1, at chromosome 1q22, determines susceptibility to diffuse-type gastric cancer. Gastroenterology. 2011;140(3):892-902.

28. Mocellin S, Verdi D, Pooley KA, Nitti D. Genetic variation and gastric cancer risk: a field synopsis and meta-analysis. Gut. 2015;64(8):1209-19.

29. Xu Q, Yuan Y, Sun LP, Gong YH, Xu Y, Yu XW, et al. Risk of gastric cancer is associated with the MUC1 568 A/G polymorphism. International journal of oncology. 2009;35(6):1313-20.

30. Jia Y, Persson C, Hou L, Zheng Z, Yeager M, Lissowska J, et al. A comprehensive analysis of common genetic variation in MUC1, MUC5AC, MUC6 genes and risk of stomach cancer. Cancer causes \& control : CCC. 2010;21(2):313-21.

31. Skierucha M, Milne AN, Offerhaus GJ, Polkowski WP, Maciejewski R, Sitarz R. Molecular alterations in gastric cancer with special reference to the early-onset subtype. World journal of gastroenterology. 2016;22(8):2460-74.

32. Forman D, Burley VJ. Gastric cancer: global pattern of the disease and an overview of environmental risk factors. Best practice \& research Clinical gastroenterology. 2006;20(4):633-49.

33. Tanikawa C, Urabe Y, Matsuo K, Kubo M, Takahashi A, Ito H, et al. A genome-wide association study identifies two susceptibility loci for duodenal ulcer in the Japanese population. Nature genetics. 2012;44(4):430-4, S1-2.

34. Lochhead P, Frank B, Hold GL, Rabkin CS, Ng MTH, Vaughan TL, et al. Genetic variation in the prostate stem cell antigen gene and upper gastrointestinal cancer in white individuals. Gastroenterology. 2011;140(2):435-41.

35. Lu Y, Chen J, Ding Y, Jin G, Wu J, Huang H, et al. Genetic variation of PSCA gene is associated with the risk of both diffuse- and intestinal-type gastric cancer in a Chinese population. International journal of cancer. 2010;127(9):2183-9.

36. Freedman N.D., Chow W.H., Gao Y.T., et al. Menstrual and reproductive factors and gastric cancer risk in a large prospective study of women. Gut. 2007;56:1671-7.

37. Reiter RE, Gu Z, Watabe T, Thomas G, Szigeti K, Davis E, et al. Prostate stem cell antigen: a cell surface marker overexpressed in prostate cancer. Proceedings of the National Academy of Sciences 
of the United States of America. 1998;95(4):1735-40.

38. Sakamoto H, Yoshimura K, Saeki N, Katai H, Shimoda T, Matsuno Y, et al. Genetic variation in PSCA is associated with susceptibility to diffuse-type gastric cancer. Nature genetics. 2008;40(6):730-40.

39. Saeki N, Gu J, Yoshida T, Wu X. Prostate stem cell antigen: a Jekyll and Hyde molecule? Clinical cancer research : an official journal of the American Association for Cancer Research. 2010;16(14):3533-8.

40. Siegmund SV, Singer MV. [Effects of alcohol on the upper gastrointestinal tract and the pancreas-an up-to-date overview]. Zeitschrift fur Gastroenterologie. 2005;43(8):723-36.

41. Brenner H, Rothenbacher D, Bode G, Adler G. Inverse graded relation between alcohol consumption and active infection with Helicobacter pylori. American journal of epidemiology. 1999;149(6):571-6.

42. Tramacere I, Negri E, Pelucchi C, Bagnardi V, Rota M, Scotti L, et al. A meta-analysis on alcohol drinking and gastric cancer risk. Annals of oncology : official journal of the European Society for Medical Oncology. 2012;23(1):28-36.

43. Bagnardi V, Rota M, Botteri E, Tramacere I, Islami F, Fedirko V, et al. Alcohol consumption and sitespecific cancer risk: a comprehensive dose-response meta-analysis. British journal of cancer. 2015;112(3):580-93.

44. Tong GX, Liang H, Chai J, Cheng J, Feng R, Chen PL, et al. Association of risk of gastric cancer and consumption of tobacco, alcohol and tea in the Chinese population. Asian Pacific journal of cancer prevention : APJCP. 2014;15(20):8765-74.

45. Knoll MR, Kolbel CB, Teyssen S, Singer MV. Action of pure ethanol and some alcoholic beverages on the gastric mucosa in healthy humans: a descriptive endoscopic study. Endoscopy. 1998;30(3):293301.

46. Yoshikazu Nishino, Manami Inoue, Ichiro Tsuji, XXXX. Tobacco Smoking and Gastric Cancer Risk: An Evaluation Based on a Systematic Review of Epidemiologic Evidence among the Japanese Population. Japanese Journal of Clinical Oncology. 2006;36(12):800-7.

47. González CA, Pera G, Agudo A, XXXX. Smoking and the risk of gastric cancer in the European Prospective Investigation Into Cancer and Nutrition (EPIC). Int J Cancer. 2003;107(4):629-34.

48. Hoffman D., Hoffman I. Chemistry and toxicology. Cigars: health effects and trends, smoking and tobacco control monograph. National Cancer Institute, Bethesda1998. p. 55-97.

49. Dyke G.W., Craven J.L., Hall R, XXXX. Smoking-related DNA adducts in human gastric cancers. Int J Cancer. 1992;52(6):847-50.

50. Boccia S, Sayed-Tabatabaei FA, Persiani R, Gianfagna F, Rausei S, Arzani D, et al. Polymorphisms in metabolic genes, their combination and interaction with tobacco smoke and alcohol consumption and risk of gastric cancer: a case-control study in an Italian population. BMC Cancer. 2007;7(1):206.

51. Zhang X-M, Zhong R, Liu L, Wang Y, Yuan J-X, Wang P, et al. Smoking and COX-2 functional polymorphisms interact to increase the risk of gastric cardia adenocarcinoma in Chinese population. PLoS One. 2011;6(7):e21894-e. 
52. Yang JJ, Ko KP, Cho LY, Shin A, Gwack J, Chang SH, et al. The role of TNF genetic variants and the interaction with cigarette smoking for gastric cancer risk: a nested case-control study. BMC Cancer. 2009;9:238.

53. Xu X, Padilla MT, Li B, Wells A, Kato K, Tellez C, et al. MUC1 in macrophage: contributions to cigarette smoke-induced lung cancer. Cancer Res. 2014;74(2):460-70.

54. Rokkas T SP, Pistiolas D, Margantinis G, Koukoulis G. . Helicobacter pylori infection and gastric histology in first-degree relatives of gastric cancer patients: a meta-analysis. . Eur J Gastroenterol Hepatol. 2010;22:1128 - 33.

55. Dhillon PK, Farrow DC, Vaughan TL, Chow WH, Risch HA, Gammon MD, et al. Family history of cancer and risk of esophageal and gastric cancers in the United States. International journal of cancer. 2001;93(1):148-52.

56. Bernini M BS, Roviello F, Scarpa A, Moore P, Pedrazzani C, Beghelli S, Marrelli D, de Manzoni G. Family history of gastric cancer: a correlation between epidemiologic findings and clinical data Gastric Cancer 2006;9:9 - 13.

57. Garcia-Gonzalez MA, Lanas A, Quintero E, Nicolas D, Parra-Blanco A, Strunk M, et al. Gastric cancer susceptibility is not linked to pro-and anti-inflammatory cytokine gene polymorphisms in whites: a Nationwide Multicenter Study in Spain. Am J Gastroenterol. 2007;102(9):1878-92.

58. Lissowska J, Groves FD, Sobin LH, Fraumeni JF, Jr., Nasierowska-Guttmejer A, Radziszewski J, et al. Family history and risk of stomach cancer in Warsaw, Poland. European journal of cancer prevention : the official journal of the European Cancer Prevention Organisation (ECP). 1999;8(3):223-7.

59. Bakir T, Can G, Erkul S, Siviloglu C. Stomach cancer history in the siblings of patients with gastric carcinoma. European journal of cancer prevention : the official journal of the European Cancer Prevention Organisation (ECP). 2000;9(6):401-8.

60. Bakir T, Can G, Siviloglu C, Erkul S. Gastric cancer and other organ cancer history in the parents of patients with gastric cancer. European journal of cancer prevention : the official journal of the European Cancer Prevention Organisation (ECP). 2003;12(3):183-9.

61. Palli D, Russo A, Ottini L, Masala G, Saieva C, Amorosi A, et al. Red meat, family history, and increased risk of gastric cancer with microsatellite instability. Cancer Res. 2001;61(14):5415-9.

62. Eto K, Ohyama S, Yamaguchi T, Wada T, Suzuki Y, Mitsumori N, et al. Familial clustering in subgroups of gastric cancer stratified by histology, age group and location. European journal of surgical oncology : the journal of the European Society of Surgical Oncology and the British Association of Surgical Oncology. 2006;32(7):743-8.

63. Minami $\mathrm{Y}$, Tateno $\mathrm{H}$. Associations between cigarette smoking and the risk of four leading cancers in Miyagi Prefecture, Japan: a multi-site case-control study. Cancer science. 2003;94(6):540-7.

\section{Tables}

Table 1 Specific primers (IDT - USA) according to MUC1 polymorphisms 


\begin{tabular}{ll}
\hline Rs4072037 & 5'-AAGGCCTATGGGCAGAGAGA-3' (forward) \\
& 5'-ACGCTGCTGGTCATACTCAC-3' (reverse) \\
Rs2070803 & 5'- CTTAGCTGTCCGGGTGTGAAGT -3' (forward) \\
& 5'- TGTGGTTCTAGGCAGGAGCAAC-3' (reverse) \\
\end{tabular}

Table 2: Characteristics of respondents 


\begin{tabular}{llllllll}
\hline & Control & Case & & \multicolumn{2}{c}{ Total } & P \\
\cline { 2 - 7 } & $\mathrm{N}=304$ & $\%$ & $\mathrm{~N}=302$ & $\%$ & $\mathrm{~N}$ & $\%$ \\
\hline
\end{tabular}

\section{Gender}

\begin{tabular}{lccccccc} 
Male & 195 & 64.14 & 210 & 69.54 & 405 & 66.72 & 0.16 \\
\cline { 1 - 5 } Female & 109 & 35.86 & 92 & 30.46 & 201 & 33.28 &
\end{tabular}

Age

\begin{tabular}{lcccccc}
$<60$ & 152 & 50.00 & 148 & 49.00 & 300 & 49.50 \\
\hline$>=60$ & 152 & 50.00 & 154 & 51.00 & 306 & 50.50
\end{tabular}

\section{Personal history of gastric diseases}

\begin{tabular}{lccccccc}
\hline No & 111 & 36.51 & 140 & 47.30 & 251 & 41.83 \\
\cline { 1 - 3 } Yes & 193 & 63.49 & 156 & 52.70 & 349 & 58.17 & \\
\hline
\end{tabular}

Family history of gastric cancer

\begin{tabular}{lcccccc}
\hline No & 285 & 95.96 & 261 & 87.58 & 546 & 91.76 \\
\cline { 1 - 5 } Yes & 12 & 4.04 & 37 & 12.42 & 49 & 8.24 \\
\hline
\end{tabular}

\section{History of alcohol abuse}

\begin{tabular}{llllllll}
\hline No & 208 & 68.42 & 176 & 58.28 & 384 & 63.37 \\
\hline Yes & 96 & 31.58 & 126 & 41.72 & 222 & 36.63 \\
\hline
\end{tabular}

\section{Smoking}

\begin{tabular}{llllllll}
\hline No & 179 & 58.88 & 159 & 52.65 & 338 & 55.78 & \\
\hline Yes & 125 & 41.12 & 143 & 47.35 & 268 & 44.22 & \\
\hline
\end{tabular}

*Significantly different

Table 3: Associated gastric cancer risk of environmental factors on a logistic regression model 


\begin{tabular}{|c|c|c|c|}
\hline & Odds Ratio & $\mathrm{p}$ & $95 \% \mathrm{CI}$ \\
\hline \multicolumn{4}{|c|}{ Gender (vs Female) } \\
\hline Male & 1.56 & 0.098 & $0.92-2.64$ \\
\hline \multicolumn{4}{|c|}{ Age group (vs <60 years old) } \\
\hline$>60$ years old & 0.72 & 0.087 & $0.50-1.05$ \\
\hline \multicolumn{4}{|c|}{ Smoking (vs No) } \\
\hline Yes & 1.05 & 0.842 & $0.66-1.65$ \\
\hline \multicolumn{4}{|c|}{ Alcohol abuse (vs No) } \\
\hline Yes & 0.50 & $0.036^{*}$ & $0.26-0.95$ \\
\hline \multicolumn{4}{|c|}{ History of $H$. Pylori infection (vs No) } \\
\hline Yes & 0.42 & $0.000 *$ & $0.29-0.61$ \\
\hline \multicolumn{4}{|c|}{ Personal history (vs No) } \\
\hline Yes & 1.42 & 0.056 & $0.99-2.04$ \\
\hline \multicolumn{4}{|c|}{ Family history of gastric cancer (vs No) } \\
\hline Yes & 3.69 & $0.000^{*}$ & $1.78-7.66$ \\
\hline
\end{tabular}

*Significantly different

Table 4: Rate of genotypes and allele distribution of rs4072037 and rs2070803 


\begin{tabular}{|c|c|c|c|c|c|}
\hline & \multicolumn{2}{|c|}{ Control } & \multicolumn{2}{|c|}{ Case } & \multirow[t]{2}{*}{$\mathbf{P}$} \\
\hline & $\mathbf{N}$ & (\%) & $\mathbf{N}$ & (\%) & \\
\hline \multicolumn{6}{|c|}{ rs4072037 - MUC1 } \\
\hline GG & 37 & 12.17 & 43 & 14.24 & $0.00 *$ \\
\hline AG & 162 & 53.29 & 110 & 36.42 & \\
\hline AA & 105 & 34.54 & 149 & 49.34 & \\
\hline G allele & 236 & 38.81 & 196 & 32.45 & $0.02 *$ \\
\hline A allele & 372 & 61.18 & 408 & 67.55 & \\
\hline \multicolumn{6}{|c|}{ rs2070803 - MUC1 } \\
\hline $\mathrm{AA}$ & 40 & 13.15 & 49 & 16.23 & $0.00^{*}$ \\
\hline AG & 164 & 53.95 & 115 & 38.08 & \\
\hline GG & 100 & 32.89 & 138 & 45.69 & \\
\hline A allele & 244 & 40.13 & 213 & 35.26 & 0.09 \\
\hline G allele & 364 & 59.87 & 391 & 64.74 & \\
\hline
\end{tabular}

*Significantly different

Table 5. Genotypes and alleles of rs4072037 and rs2070803 association with gastric cancer 


\begin{tabular}{|c|c|c|c|}
\hline & Odds Ratio & $\mathbf{P}$ & [95\% Conf. Interval] \\
\hline \multicolumn{4}{|l|}{$R s 4072037$} \\
\hline $\mathrm{AG}>\mathrm{GG}$ & 0.58 & 0.04 & $0.35-0.97 *$ \\
\hline $\mathrm{AA}>\mathrm{AG}$ & 2.09 & 0.00 & $1.48-2.96^{* *}$ \\
\hline $\mathrm{AA}>\mathrm{AG}+\mathrm{GG}$ & 1.85 & 0.00 & $1.33-2.56^{* *}$ \\
\hline$A>G$ & 1.32 & 0.02 & $1.04-1.67 *$ \\
\hline \multicolumn{4}{|l|}{ Rs2070803 } \\
\hline $\mathrm{AG}>\mathrm{AA}$ & 0.51 & 0.00 & $0.35-0.72 *$ \\
\hline $\mathrm{GG}>\mathrm{AG}$ & 1.97 & 0.00 & $1.39-2.80 * *$ \\
\hline $\mathrm{GG}>\mathrm{AG}+\mathrm{AA}$ & 1.71 & 0.00 & $1.23-2.39 * *$ \\
\hline $\mathrm{G}>\mathrm{A}$ & 2.73 & 0.09 & $0.97-1.55$ \\
\hline
\end{tabular}

*Significantly different

Table 6. Genotypes of two SNP combine with environmental factors 


\begin{tabular}{|c|c|c|c|}
\hline Risk factors combines genotypes & Odds Ratio & $\mathbf{p}$ & [95\% Conf. Interval] \\
\hline \multicolumn{4}{|l|}{ Rs 4072037} \\
\hline Age $>60+\mathrm{AA}$ & 1.57 & 0.03 & $1.05-2.34^{*}$ \\
\hline Male + AA & 1.84 & 0.00 & $1.28-2.67 *$ \\
\hline Smoking + AA & 1.72 & 0.02 & $1.11-2.67 *$ \\
\hline Alcohol abuse history + AA & 2.06 & 0.00 & $1.32-3.23 *$ \\
\hline Personal history of gastritis+ AA & 1.31 & 0.16 & $0.89-1.91$ \\
\hline Family history of gastric cancer + AA & 6.47 & 0.00 & $2.21-18.89^{*}$ \\
\hline \multicolumn{4}{|l|}{$R s 2070803$} \\
\hline Age $>60+$ GG & 1.50 & 0.05 & $1.00-2.25^{*}$ \\
\hline Male + GG & 1.80 & 0.00 & $1.25-2.63^{*}$ \\
\hline Smoking +GG & 1.68 & 0.02 & $1.07-2.63^{*}$ \\
\hline Alcohol abuse history + GG & 1.98 & 0.00 & $1.22-3.04^{*}$ \\
\hline Personal history of gastritis + GG & 1.22 & 0.31 & $0.83-1.80$ \\
\hline Family history of gastric cancer + GG & 6.18 & 0.00 & $2.11-18.10^{*}$ \\
\hline
\end{tabular}

*Significantly different

\section{Figures}



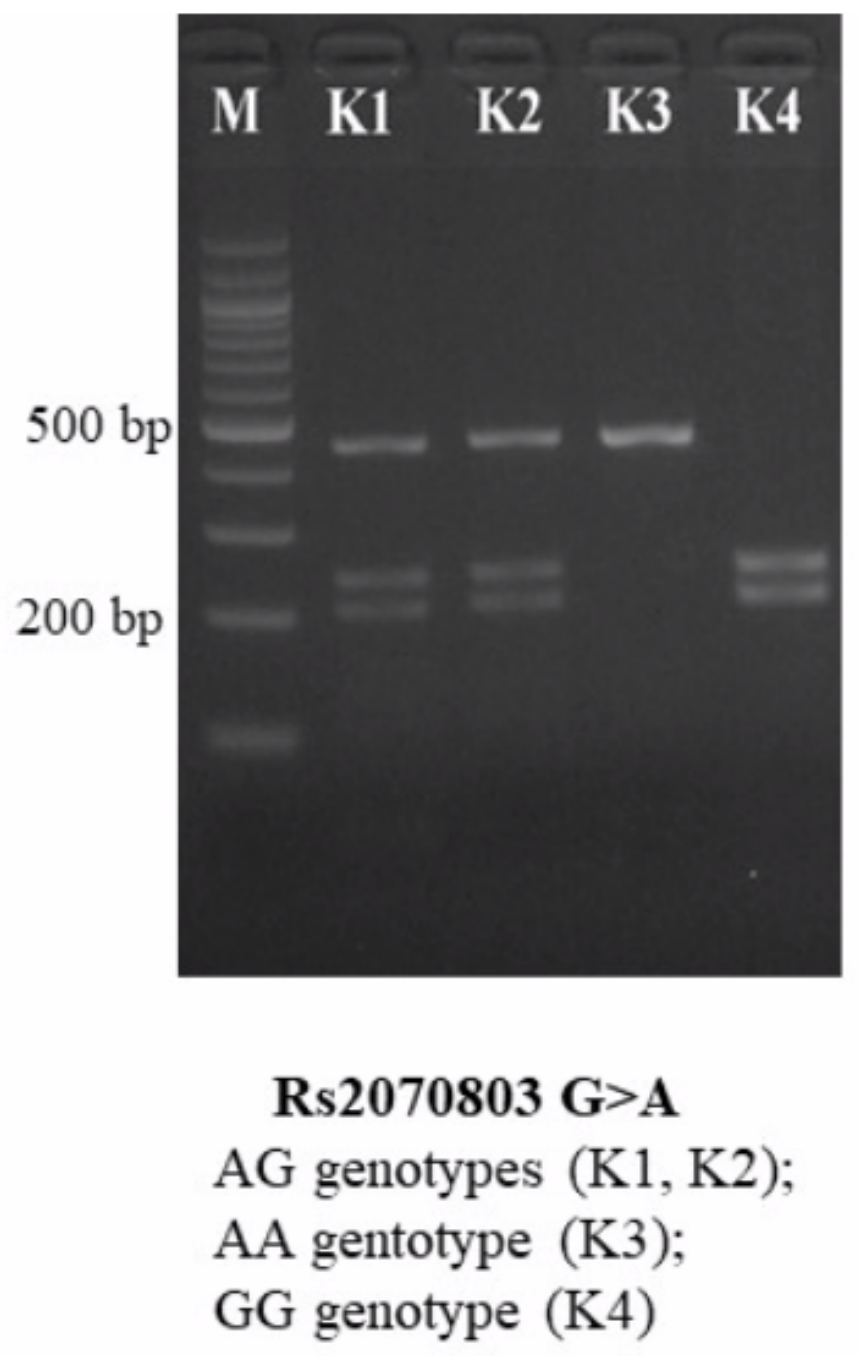

Rs2070803 G>A

AG genotypes (K1, K2); AA gentotype (K3); GG genotype (K4)

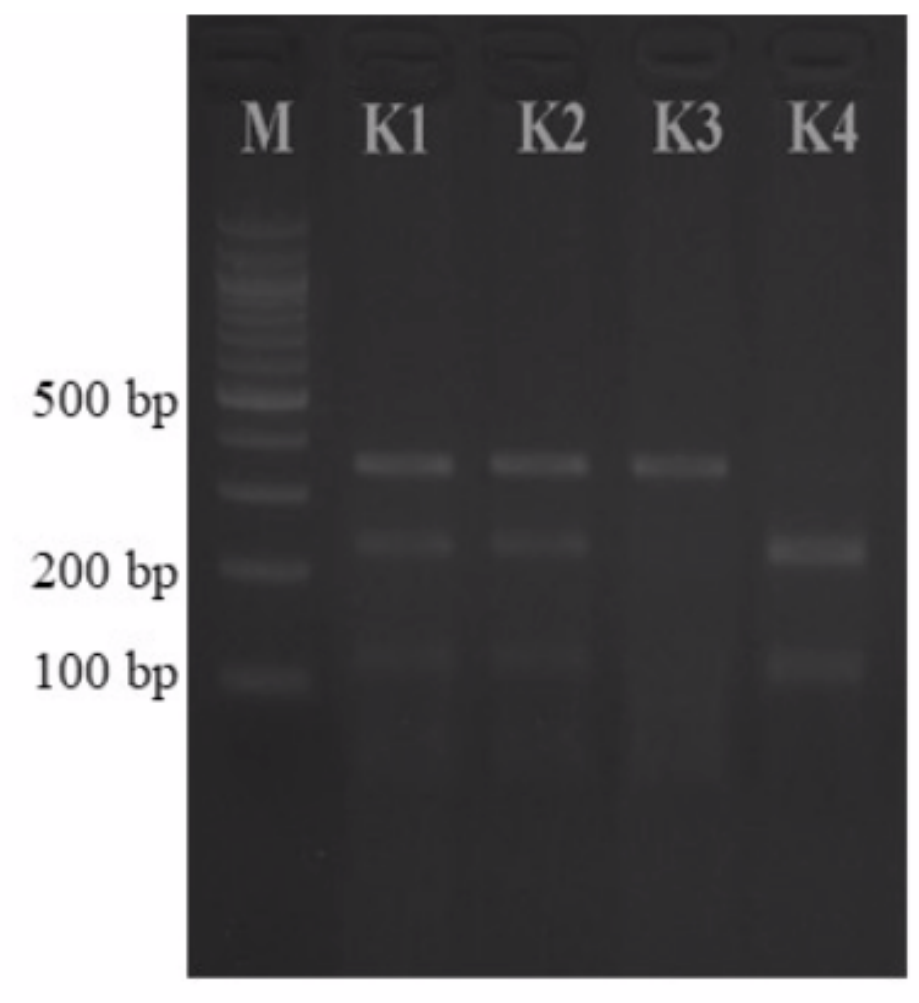

Rs4072037 A>G
AG genotypes (K1, K2);
GG gentotype (K3);
AA genotype (K4)

